\title{
Imagining Futures: a Methodological Perspective for Digital Design
}

XXIV International Conference of the Iberoamerican Society of Digital Graphics Medellin | Colombia

\author{
Marta D'Alessandro \\ ABC Department, Politecnico di Milano | Italy | marta.dalessandro@polimi.it \\ Óscar Cruz \\ ETSAM, Universidad Politécnica de Madrid | Spain | oscar.cruz.garcia@alumnos.upm.es \\ Ingrid Paoletti \\ ABC Department, Politecnico di Milano | Italy | ingrid.paoletti@polimi.it
}

\begin{abstract}
Imagining future(s) is a culturally relevant practice throughout all the ages and different social domains. Cultures develop their own imagine of future through several practices that unfold the present. The available design technologies have a primary role in this construction process, driving and altering the vision of what is imagined. Visionary images of the future, whether induced by drawing or other techniques, are real agents of social change. This paper provides a theoretical approach to futures oriented design practices through the analisis of the outcomes of the Imagining Future(s) workshop at Foster Foundation (Madrid) and outlines three methodology tracks detected during the exercize.
\end{abstract}

Keywords: Digital Culture; Imagination; Future Studies; Technological Culture; Vision

\section{INTRODUCTION}

The Aymara, Ameriandian language spoken in the Andean highlands of Western Bolivia, southeastern Peru, and Northern Chile, presents a fascinating and unattested-inother-languages characteristic: in Aymara, the word back (qhipa) is a basic expression for future meaning. Similarly, a series of linguistic constructs show that the space-time concept of the Aymara-speaking populations is completely overturned: "with the future behind them", as stated by Núñez \& Sweetser (2006). Andrea Sgarro (2016), theoretical computer scientist, identifies some similar constructs' tracks in the Ancient Greek. However, Aymara appears to be the first well-documented case presenting a "genuine fundamental difference in the organization of time constructions" (Núñez \& Sweetser 2006, p. 403). Such a linguistic peculiarity implies that for an entire culture the past is before the eyes, being all that we can see, while the future is behind humans, corresponding to the blind and defensless part of our body. Natural intelligence of languages is surprising. Núñez \& Sweetser (2006) notice that, if we exclude some anomalous linguistic constructions that fall within the posteriority constructs (reference to one time as being later in a sequence than another), all languages use metaphorical temporal constructs that position the future in front of us, in front of our eyes, assuming that future is something we can see clearly. We just have to figure it out.

A primary tool to deal with future is imagination. Imagination is a difficult domain to circumscribe. Simply defined it is the ability of human to create internal pictures of objects or situations. In its current use the term suggests the link with a future time, but etimologically, the corresponding word to image in Latin (imago) as well as some verbs of the Ancient Greek from which the Latin word imago is traced back, as

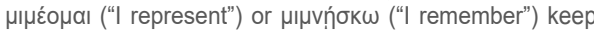
traces of the same Indo-European root *aim which covers a series of meanings that move back and forth between past and future.

The role of imagination in human cognitive activities had already emerged with modern capital philosophers as Immanuel Kant or Friedrich Hegel, between $18^{\text {th }}$ and $19^{\text {th }}$ century. Currently, the role of imagination as a driver to act in such a contingent world is promoted by several fields, as Neuroscience (Damasio, 2001), Art and Design (Pendleton-Jullian \& Brown, 2016) and Technology (ibid.), among others. Indeed, imagining futures is a culturally relevant practice throughout all the ages and different social domains. It is strongly connected to material and technological fields. Cultures do not simply imagine futures in a narrow sense but they make it through different practices that unfold the present (Konrad \& Böhle, 2019). Currently, in architecture and design fields, the transformative approach can be included among these envisioning practices, as it constitutes a means of continually responding, adapting and innovating the architectural response for ongoing and future change.

This paper analyses the outcome of the Imagining Futures programme at Foster Foundation Madrid, that has engaged post-graduated students from the Escuela Técnica Superior de Arquitectura de Madrid (ETSAM), Universidad Politécnica de Madrid, and the Department of Architecture, Built Environment and Construction Engineering (ABC), Politecnico di Milano, from 17th to 21st February 2020. Taking the chance of the cultural events and the promotion of Leonardo da Vinci scientific and artistic production, at the five-hundredth anniversary of his death, the Imagining Futures programme provided a non-conventional design methodology inspired to Leonardo genius, in relation with the work of the great, multidisciplinary, contemporary thinker, Norman Foster. The outcome of the workshop provides a theoretical aproximation on imagining futures practice and the a posteriori analysis outlines three 
methodology tracks to aid the exploration of design alternatives.

\section{IMAGINATION AND DIGITAL CULTURE: KNOWING THE UNKNOWN}

From the mid-20th century, designers have been concerned with the use of digital design technologies, exploring new formal and technological possibilities, but above all a more efficient working process. In this context, digital tools are generally assumed as "representational devices at the service of human creativity and interpretations" (Terzidis 2003, p. 2). However, the idea that digital devices are not just tools for exploring what is already known begins taking shape: providing new spatial and corporeal practices, digital technologies could be considered as "portals for entering into what is unknown" (ibid). The digital turn that has been taking place in all the fields of human practice represents a force capable to radically change not just the design mechanism and manufacturing, but it also revolutionizes the structures of imagination. By the way, technology innovation has always produced unexpected aesthetics. For example, in the XV century the acquisition and diffusion in Europe of a basic technological artefact, the paper, constituted a revolution in the exploration curried on by artists: they were allowed to explore both internal and external world using a less dogmatic drawing, the sketch. This allowed geniuses such as Leonardo da Vinci or Michelangelo Buonarroti to bring their mental virtual product to life. Similarly, many technologies could be considered as imagination and innovation driver.

The research reported here reveals how images that designers create of futures are influenced by the use of digital tools and by imageries strongly related to the digital material. For this purpose, the results of an activity of empowering imagination are examined.

\section{IMAGINING FUTURE(S)}

\section{METHODOLOGY}

The activity has been realized with groups of design professionals and scholars, who have been required to construct a vision about three everyday objects and spaces, imagining how human experience and social realities will change in the future around the transformation of three key items: the table, the house, the means of transport. The challenge was not technical or representative, but mostly conceptual and speculative. Three sets of drawings from the Norman Foster Archive, those of the Nomos Desking System, the Hampstead House and the Stansted Airport, have been taken as reference to allow designers banking mental images and then operating on those to enter into new design territory.

The activity involved two stages. In the first stage, scholars were required to carry out an abstraction process, deconstructing both physically and conceptually the elements of the existing sketches of the projects. Then, contents have been transferred to a target problem, acquiring a new structure and meaning, to create a new design concept.

\section{OUTCOMES}

\section{EXPERIENCE DEMATERIALIZATION}

"Rethinking Nomos" is a speculation on the ontology of the table, proposed by the architects A. Caraballo, Ó. Cruz and P. K. Neng. The design of Nomos Desking System had already blurred the physical line that divides two universes of function and meaning, the above and the below, as its transparent top turns into a vertical plane.

The proposal represents a further upheaval. The top of the table disappears at all. The activities that commonly orbit the table plane merge into a cloud of functions. The structure leaves its static form and embraces the movement, evolving into an organism that adapts and responds to a larger number of possible functions. The table is condensed in a dynamic spine, where vertebras of different animal species deploy different table section. The table becomes an evolving organism.

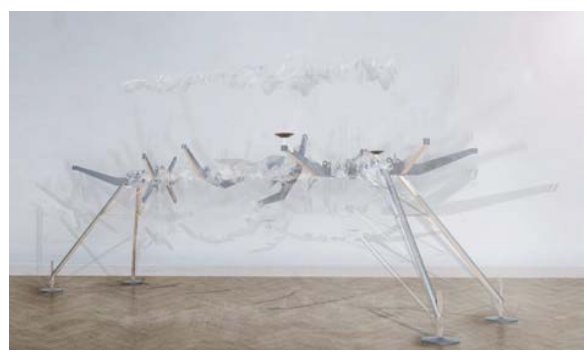

Figure 1: Rethinking Nomos. A. Caraballo, Ó. Cruz, P. K. Neng (2020). (C) Norman Foster Foundation.

\section{IMAGERY LANDSCAPES}

Working with the Hampstead House drawings set, the architects E. Álvarez. L. C. Shean and J. Mateos, wonder if the outside physical world will exist in the future. It would be frizening if waking up, one morning, there were not an outside, nothingness from our windows. Our digital lives constantly keep us at the edge of a dystopic reality, in which our most intimate data is transformed into bits, more and more difficult to protect, and our clarity is jeopardized. This has a range of effects on a number of design scales. The house of the future turns inwards to provide its inhabitants an infinite range of experiences. The Hampstead House is the place that Norman and Wendy Foster designed for their own, and it never materialized. Therefore, it is an open work, without the limitations that matter confers (Solé Bravo, 2014, p. 241). The caring drawing of the original house contains the physical and mental universe of its authors. Its reinterpretation involves a hyper-technological envelope defined in the smallest, real and imaginary, details. Those devices bloom on the original modules, like post-human superfetations. The future Hampstead House is a Noah's Ark of imagery landscapes. 


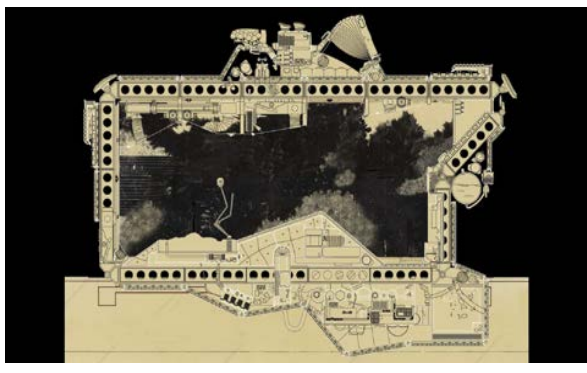

Figure 2: Jia | House | Casa. E. Álvarez, L. C. Shean, J. Mateos (2020). ( N Norman Foster Foundation.

\section{CLOUD METAPHOR}

The Stansted Airport becomes a cloud in the non-gravity, or even non-ground, scenario of the architects G. Dede, A. Gómez and B. Ruiz. The metaphor of the cloud as a weightless and volatile infrastructure to access only by cleaner and efficient devices moves from IT field to the vision of a vibrating branching structure. The original structure modules are combined vertically, riding the city of inert surfaces. A cable system binds the new airport to the earth's surface, but what guarantees its position is a kites system that uses the currents of the stratosphere to keep the artificial cloud in place. The modules turn into individual flying devices.

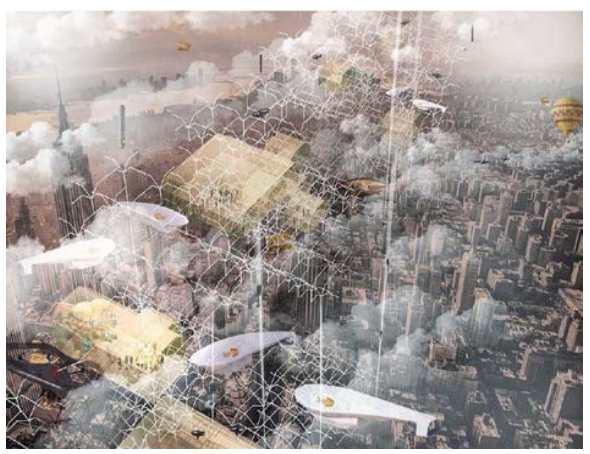

Figure 3: Inhabiting the Air. G. Dede, A. Gómez, B. Ruiz (2020). (C) Norman Foster Foundation.

\section{RESULTS}

Literature widely reports the design practices that digital approaches can address, being the design generation, evaluation and alternative selection the main ones. However, there is a more intimate level of the design process on which digitization strongly affects: the imagination.

\section{IMAGINING FUTURE: PERCEIVED MEMORIES COLLECTION}

The present that we live is the imagined future failed by humans in the past. We carry on imagining the same future as before as if it were the future we own imagine. Exploiting the possibilities of new technologies, our imagination process feeds on a new catalogue of mental images made possible by digital design tools. However, there is a breaking point, as the creative contingency that mainly manifests through the subject (designer) benefits from a series of connected practices in which the tools take on, from time to time, a different level of autonomy and influence on the designer's activity. Stretching an approach in which the design solution emerges and evolves autonomously, it is possible to wonder what if there were a lack of predictability over what was imagined by the designer and what came out on the reality? Would still be valid to assume that a designer is in control of the impact of its imagination?

\section{METHODOLOGY TRACKS}

\section{IMAGINING BY AUXILIARY STRUCTURES}

\begin{abstract}
"In the Biblical covenant between God and human there is a fundamental clause: "Let it be clear" says God "that Creator is just me, that created you, and are not you. I am, about this point, a jealous God ".
\end{abstract}

Enzo Paci, Diario fenomenologico, II Saggiatore, Milano 1961, pp. 95-97 (authors' translation)

The appearance of images on earth is probably one of the most mysterious event of human existence and survival. Their diffusion has had several tormented periods, as the imagination ability and consequently, the imagine production, is religiously related with the act of Creation. In his book "The Thinking Hand, Existential and Embodied Wisdom in Architecture", Juhani Pallasmaa (2009) considers as real both the image perceived in a corporeal way, and the stored and re-produced images, elaborated through the memories collection that inhabits us (fig. 4). Thus, human imagination is not a pure creation act. It is constantly supported by external representation. According to Eastman (2001, p. 6) those auxiliary structures support the internal representation in the mind of the designer. They are integrated in the complex design's cognitive system, constituting continuous feedback to the imagination activity. 


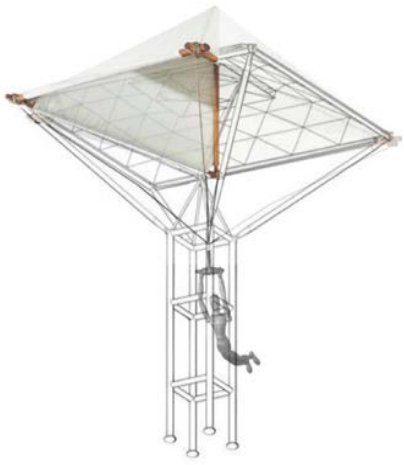

Figure 4: Imagining by auxiliary structure in "Inhabiting the Air" vision by G. Dede, A. Gómez, B. Ruiz (2020). (c) Norman Foster Foundation.

Imagination supposedly involves a range of actions as perceiving, memory retrieving, mentally simulating, future thinking (Jung et al., 2016) among others. This could limit the imagination effects, conditioning to a concrete-oriented, prudently incremental, imagination activity. Under these conditions, everything imaginable would already be in our mind. Possible way to address this issue is learning to look. An intentional gaze that seeks beyond the obvious, going beyond the eroticism of the image itself. Learning to look, study and dissect through the senses, just as learning to filter through drawing. Drawing is nothing more than a glance projected and filtered by the bodily memory that the hand executes. A memory apprehended during a trip: the perceived experience.

The human being continues to imagine the same future as in the past, but his battery of images has been updating from time to time thanks to current technology. The latter has been imbued with social meaning, that allowed organizing all social system around it. Human speculates with flying vehicles as a "concept" and due to the time he imagines them differently. As it happens for the digital technology, after inventing the airplane humans have defined a new way of life around the airplane possibilties.

If the future that we are capable of imagining is already present in our daily images, we should speculate with those images in a radical way. Doing that, following a logical process starting from abstraction until reaching a reality and imagination unattainable from our own standardized design of the "in crecendo" process.

\section{IMAGINING BY REDUCING GRAPHICAL INFORMATION}

[...] Socio-technical futures and their underlying assumptions do not need to be explicit though. They may be implicit in visions and imaginaries, in the design of artefacts and systems, the set-up of projects, in forecasts and assessment practices. ) [...]

(Konrad and Böhle, 2019, p.)

Future-oriented design problems are generally not routine problems: their component could not be taken apart and put together again; they change dynamically. To address this problems designers use unclear and indeterminate information as clues for evolving their design ideas (Smith et al., 2017). Indeed the ambiguous nature of graphical information produced during the early stage of design facilitates ideas transformation; helps to develop design alternatives; supports multiple interpretations; plays an important role for the designer cognitive process, supporting the exploration of a variety of ideas.
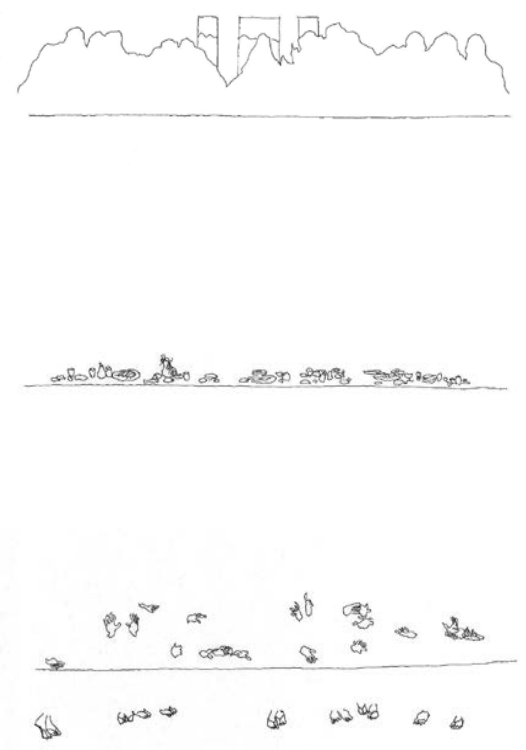

Figure 5: Imagining by reducing graphical information of The Last Supper, Leonardo da Vinci (1490s) in Rethinking Nomos proposal by A. Caraballo, Ó. Cruz, P. K. Neng (2020). (C) Norman Foster Foundation.

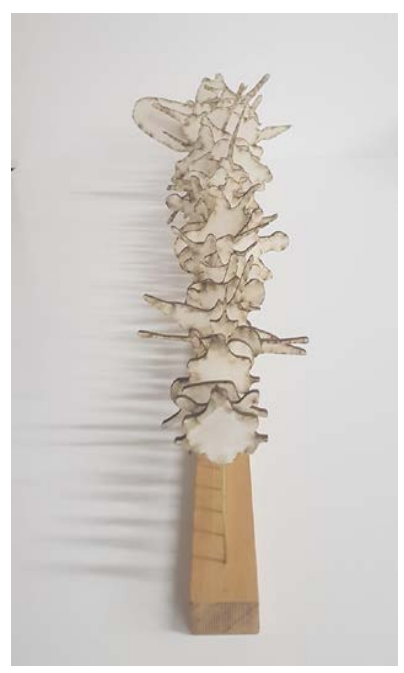

Figure 6: Rethinking Nomos. A. Caraballo, Ó. Cruz, P. K. Neng (2020). ( ) Norman Foster Foundation. 
The results of the speculation activity around ambiguous graphical information is often unrelated to any specific or contingent reality. They are generally visionary drawings, representing a frame that does not exist or may never exist. However, thanks to their impact, they could be strongly influential.

Is probably this reinterpretation or interconnection of images through abstraction that re-teaches how to look within the chaotic world of information overexposure? Or is it simply the element that underlies the essence of things that has the track of their future vocation, the invariant element of their evolution?

Essence or character transmit a future projection, an "I am" or "I will be" but they are forgetting "I have been". If so, the discriminated dissection of the concept or element by means of drawing, which in itself implies a bodily experience based on the memory of the body, complements the retinal imagination and cleanses it through skill and the filter of the hand.

Justifying this imagination-perceived visual image link, we just have to close our eyes and remember the image excavated in our heads when listening to a noise. We are able to "create" or reconstruct a space through the action that noise has generated simply with memory based on experience. We rebuild the streets of the city when listening to an ambulance in the middle of the night, and we are able to find out where it is simply by the wear and tear of its sound.

If our future comes from our imagination and it draws from the visual experience lived but transmitted or narrated through the filter of the drawing that starts from our bodily being, the future will be the projection of a catalogue of images modified by the present "need", reason why the external agents of the human condition are changing, not by themselves alone, but by our actions.

In other words, the condition of an uncertain future based on bodily experience, dialogue and negotiation with an environment is underlined.

\section{RADICAL IMAGINATION}

In their theoretical construct "The Three Tomorrows of Postnormal Times", Ziauddi and Sweeney (2016) describe three future horizons: the extended present (5-10 years), Camo the familiar future(s) (10-20 years), the un-thought future(s) (it extends beyond the next 20 years). Designers often use Carpo, M. (2012). The Digital Turn in Architecture 1992-2012. transformative approaches in order to analyse trends and propose resilient solutions. However when they try to deliberately imagine future scenarios, even extended present ones, it emerges that future is not necessarily a natural continuation of the present. Radicalism as a strategy for imagining futures activity emphasizes the Eastman, C. (2001). New directions in design cognition: Studies of concept that the future is not the continuation of the present. Makes you think that what seemed to be an un-Jung probably or distant project context during the workshop (as earth as a no fly zone or introverted home landscape) became reality few days after, with the unexpected spread of the covid-19 pandemic.

\section{DISCUSSION}

The focus on linguistic construction of time, at the opening of the document had a specific purpose. As it is the first computational tool, language allows analysing and measuring the subject's experience (Sini, 2009). This unfolds in time and space perception. And this perception feeds memory and negotiates futures. Future is a dynamic entity that constantly change. Visionary images of the future, whether induced by drawing or other techniques, are real agents of social change. The nature of the relationship linking these images to the cultures that inspire or are inspired by them depends on the attribution of a weight of significance. This significance depends on the present values in a specific period and on the negotiation. Approaching these images in the light of the critique of the great division between nature and culture, the intersection of biological and social processes take place as a transformations, in the global panorama.

The resulting proposals of the imagination activity presented have shown that designers which operate in such a contingent situation are required to see objects with new eyes, identifying not obvious connections and a quite elusive meaning. It is possible to detect a design process inextricably linked to a digital imagery universe and systematize the analysis to define a methodological perspective beyond methodological tracks already defined, within the transformative design frame. Retracing the symbolic dimension that digital has on design, the outlined methodology has the specific functions of aiding the exploration of alternative futures

Technology plays a key role in the cultural transformation of design practice and imagination. According to Camorrino (2017) technology could even play a deterministic role in the metamorphosis of reality. Every epoch needs imagination; our epoch faces a crisis of imagination right now that it has become indispensable, as science and industry are constantly producing a frightening amount of new possibilities. Having agency in this scenarios, designers must break the usual patterns of thinking and construct narratives to communicate their vision about the future of architecture.

\section{REFERENCES}

Arbeláez Ochoa, E. M. (2015). Design as an eminently practical, transformative and communicative discipline. Iconofacto, 11(17), 74-80.

Birkhofer, H. (2011). The Future of Design Methodology. London: Springer.

amorrino, A. (2017). An Apparent Immateriality. Sociological Analysis of Digital Imagination. S\&F, (n. 18), 135-146

Hoboken: John Wiley \& Sons Inc.

amasio, A. R. (2001) Some notes on brain, imagination and creativity. In K.H. Pfenninger, V. R, Shubik (Eds.), The Origin of Creativity (pp. 59-62). Oxford: Oxford University Press

representation and recall. Elsevier.

ung, R. E., Flores, R. A., \& Hunter, D. (2016). A New Measure of Imagination Ability : Anatomical Brain Imaging Correlates, 7 (April), 1-8. https://doi.org/10.3389/fpsyg.2016.00496

Knight M., Dokonal W., Brown A. and Hannobal C. (2005) Contemporary Digital Techniques in the Early Stages of Design, Computer Aided Architectural Design Futures. Proceedings of the 11th International Conference on Computer Aided Architectural Design Futures, Vienna, Austria, 165-174.

Konrad, K., \& Böhle, K. (2019). Socio-technical futures and the governance of innovation processes - An introduction to the special issue. Futures, 109 (March), 101-107. https://doi.org/10.1016/j.futures.2019.03.003 
Núñez, R. E., \& Sweetser, E. (2006). With the Future Behind Them: Convergent Evidence From Aymara Language and Gesture in the Crosslinguistic Comparison of Spatial Construals of Time, $30,401-450$.

Paci, E. (1961) Diario fenomenologico. Milano: II Saggiatore.

Pallasmaa, J. (2009) The Thinking Hand, Existential and Embodied Wisdom in Architecture. Hoboken: John Wiley \& Sons.

Pendleton-Jullian A., Brown J.S. (2016). Pragmatic Imagination: Single from Design Unbound. Blurb.

Popper, K. R. (1972). Objective Knowledge: An Evolutionary Approach (Revised Edition). Oxford: University Press.

Samli, C. A. (2011). From Imagination to Innovation: New Product Development for Quality of Life. London: Springer.
Sardar, Z., \& Sweeney, J. A. (2016). The Three Tomorrows of Postnormal Times. Futures, 75, 1-13. https://doi.org/10.1016/j.futures.2015.10.004

Sgarro, A. (2016). Divagazioni sul futuro: ci sta dietro o ci sta davanti?, 13, 21-25. https://doi.org/10.13137/2039$8646 / 13815$

Smith, N., Inoue, S., Spencer, N., \& Tennant, A. (2017). Student's imagination Creative puzzlement: how deconstructing elements of object facilitates industrial design student's imagination. The Design Journal, 6925, S859-S874. https://doi.org/10.1080/14606925.2017.1353032

Solé Bravo, C. (2014). Expresionismo tecnológico: Norman Foster en Hampstead. Dearq 15, 240-249.

Terzidis, K. (2003). Expressive form: A conceptual approach to computational design (1 edition). London: Routledge. 